\title{
COVID-19 PANDEMIC AND PERSPECTIVE CONVERGENCE WITH PERIODONTAL DISEASES
}

\author{
Asem Mohamed Kamel ${ }^{1}$, Ibrahim M. Mwafey ${ }^{1}$, Ibrahim H. Ibrahim ${ }^{1}$, Ahmed Hussein Gaber ${ }^{2}$ \\ ${ }^{1}$ Department of Oral Medicine, Periodontology, Oral diagnosis and dental radiology, Faculty of Dental \\ Medicine Al-Azhar University (Assiut branch) Assiut, Egypt \\ ${ }^{2}$ Department of Oral Pathology Faculty of Dental Medicine Al-Azhar University (Assiut branch) Assiut, \\ Egypt \\ *Corresponding author: asemali.dent.ast.b@azhar.edu.eg
}

\begin{abstract}
This review aim to discuss the important components of Coronavirus Disease (COVID-19) and possible correlations, interactions with oral/periodontal structures. With the beginning of the announcement of the transformation of COVID-19 from an epidemic into a pandemic, it was necessary to realize the injury of several million people infected with this disease and others will become infected soon and its impact on public health as well as the adverse effect of chronic diseases and their causes for the spread of COVID-19. Chronic periodontal diseases are one of the most widespread diseases around the globe and one of their supposed causes is the presence of many microbial plaques, including bacteria and viruses. Presence of coronavirus receptors on the cells of the oral mucosa, and cells of the periodontal pockets, may give a way to adhere the virus and spread inside the body through the periodontium. SARS-CoV-2 virus was found in some saliva samples. A conceivable relevance between periodontitis and COVID-19 has been hypothesized. Defense against COVID-19 in dental clinical consist of three ascending levels. It is advised to utilize a mouth rinse against SARS-CoV-2. At end of this review, oral health providers and periodontists will gain essential knowledge to the successful confrontation against the Coronavirus Disease (COVID-19).
\end{abstract}

Keywords: SARS-CoV-2, COVID-19, periodontal diseases, Pandemic. 


\section{Introduction}

In association with specific bacterial pathogens like red complex bacteria, etiopathogenesis of periodontal diseases may include many viruses as active herpesviruses, and it associated with unbalanced immune restraint including pro/anti-inflammatory cytokines (Slots 2015). Some viruses like Herpesviruses act by infect or alter periodontium components and immune cells within periodontium and thereby decease efficiency of periodontal tissues to overcome bacterial overloads (Contreras et al., 2014).

Synergistic effects of viruses enhance microbial replication or infectivity of another microbes. The human immunodeficiency virus (HIV) with specific Epstein-Barr virus (EBV) progenies show growing replication within CD-4 cells (Zhang et al. 1997). with assisting of herpes simplex virus (HSV)-1, HIV can enter keratinocytes, which are commonly avoider to invasion as these cells don't have the CD4 molecule (Heng et al., 1994).

The aftermost evidence for a possible microbial correlation between human herpesvirus 4 (EBV) and some periodontpathogenomic bacteria in periodontal etiopathogenesis was reported in observations suggested that butyric acid by-product of periodontal bacteria have the capacity to target Epstein-Barr virus reactivation in the periodontium of EBV-infected individuals and control switching from latency to reactivation considered as an initial step in EBV infection (Imai \& Ogata, 2020). Redondoviridae, a family of tiny, annular DNA viruses newly located in metagenomic series map, can assist and persist the inflammation status associated with periodontal diseases and contribute to disease aggression via their infection and replication (Abbas et al., 2019) (figure.1).

Acute virally infected patients are showing high accretion of bacterial invasions. The study of influenza outbreaks in humans gives the clearest and strongest clue of the effect of viral infections on the spread of bacterial diseases. Streptococcus pneumonia and Staphylococcus aureus bacterial super infections result in altitude of morbidity and mortality during influenza epidemics (Abramson \& Mills, 1988) (figure.1). 


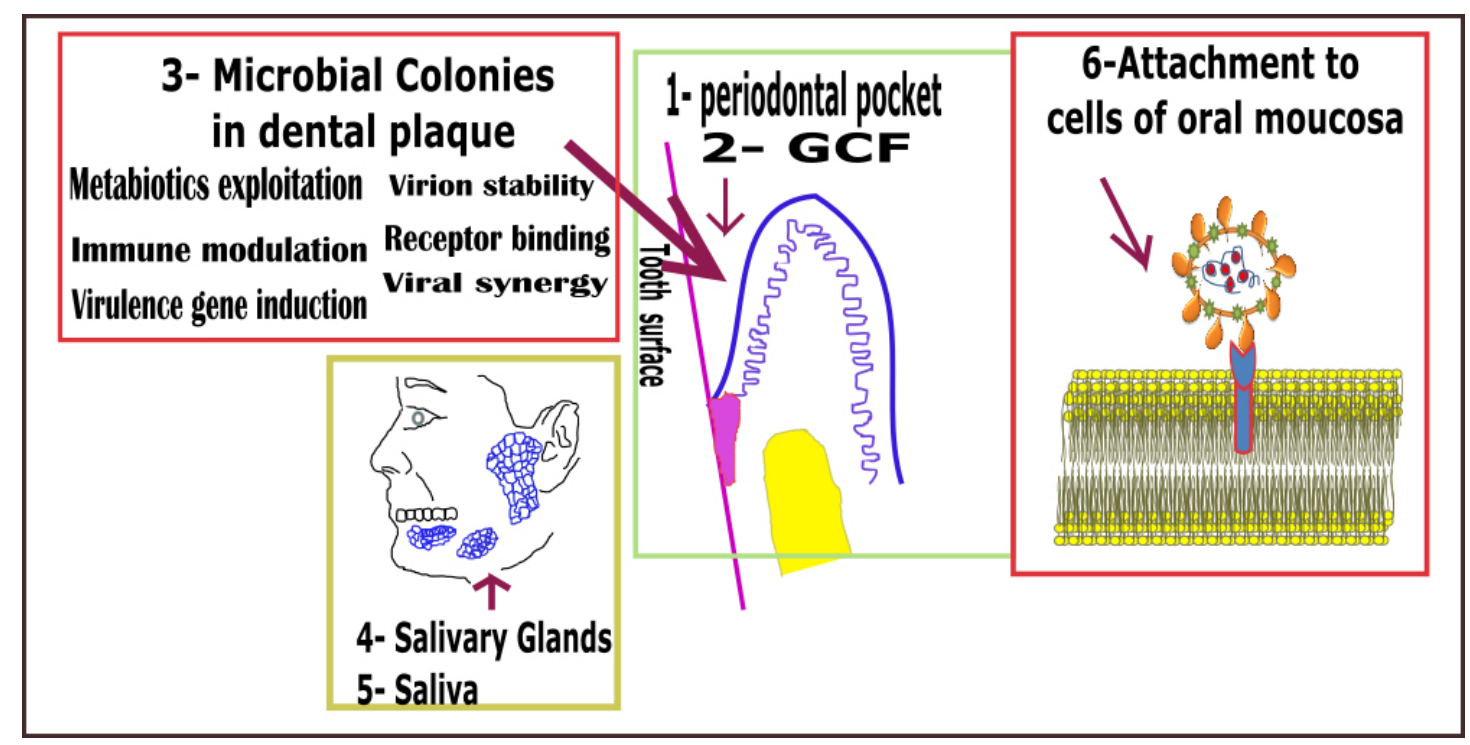

Figure.1 showing potential sites of coronavirus (SARS-CoV-2) in oral cavity and possible polymicrobial interactions between bacteria and viruses which leading to synergism, stability, coinfection, bacterial superinfection. Abbreviations; (GCF, Gingival Crevicular Fluid),

By the beginning of 2020, "World Health Organization" (WHO) termed the virus severe respiratory syndrome-coronavirus-2 (SARS-COV-2), constructing it as major outrage for acute respiratory distress syndrome (ARDS), and the malady was termed "coronavirus disease 2019 (COVID-19)". by the time, a state of COVID-19 became pandemic, and it was known as a public health contingency of international disquiet (J. Wong et al., 2020;Khongsai et al., 2020).

Coronaviruses are determined as the massive group of viruses, which being owned by the Nidovirales order, including Coronaviridae (alpha, beta, gamma, and delta), Arteriviridae, and Roniviridae families. Their main structures are coated, undivided positive-sense RNA. Digestive and respiratory sickness in animals, and fatal respiratory distress in persons can be caused as manifestations of coronavirus infection (Fehr \& Perlman, 2015). As members of Coronaviridae family, severe acute respiratory syndrome coronavirus (SARS-CoV), specified in 2002, and the Middle East respiratory syndrome coronavirus (MERS-CoV), specified in 2012 (Wax \& Christian, 2020). Newly incoming betacoronavirus (SARS-CoV-2) has resemblance to coronavirus species habituated in bats and pangolins, supporting the zoonotic essence of this recent wandering viral-mediated disease (Zhou et al., 2020; Wahba et al., 2020;PANDEY et al., 2020)

The components of SARS-COV-2 structure include a nucleocapsid(N) with a single stranded RNA core, a spherical lipoprotein envelope $(E)$ and matrix protein $(M)$ with protruding spike shape proteins $(S)$, which are adhering to specific receptors of the host cells to be infected (Gorbalenya et al., 2020) (figure.2). SARS-COV-2 needs incubation period from 1 to 14 days to be contagious in its latency interval (Pereira et al., 2020). Its replication cycle was correlated with the harmful impacts, appearing as cellular lesions and increased cell death (Earar et al. 2020). Viruses have stealth capacity to escape 
from host immune defense and to inactivate the host interferon system which interfering with pattern recognition receptors (PRRs) alerting routes to evade host defense (Kindler et al., 2016).

The SARS-CoV N proteins inhibit retinoic-acid inducible gene I (RIG-I) conjunction with ubiquitin and thus decrease the emission of type I IFN (Interferon) (Hu et al., 2017). M proteins restrains TNFRassociated factor/ TANK-binding kinase (TRAF3/ TBK1) complex formation and blocks activation of Interferon regulatory factor 3 / Interferon regulatory factor 7 (IRF3/IRF7) transcription factors (Siu et al., 2009). The SARS-CoV Nonstructural Protein (nsp1) prohibits host mRNA translation and initiates host mRNA degradation [(Tanaka et al., 2012; Huang et al., 2011).

Three routes of the SARS-CoV transmission have been found. Firstly, contact transmission: when someone touches an infected object and subsequently touches his mouth, nose or eyes. Secondly, Droplets transmission: when the droplets generated by cough and sneezes are ingested or inhaled. Finally, Airborne transmission: when air contaminated by droplets, creating aerosols that results in infection if inbreathed (Adhikari et al., 2020; Harte, 2010). Fecal-oral transmission is considered possible as well (Zhang et al., 2020).

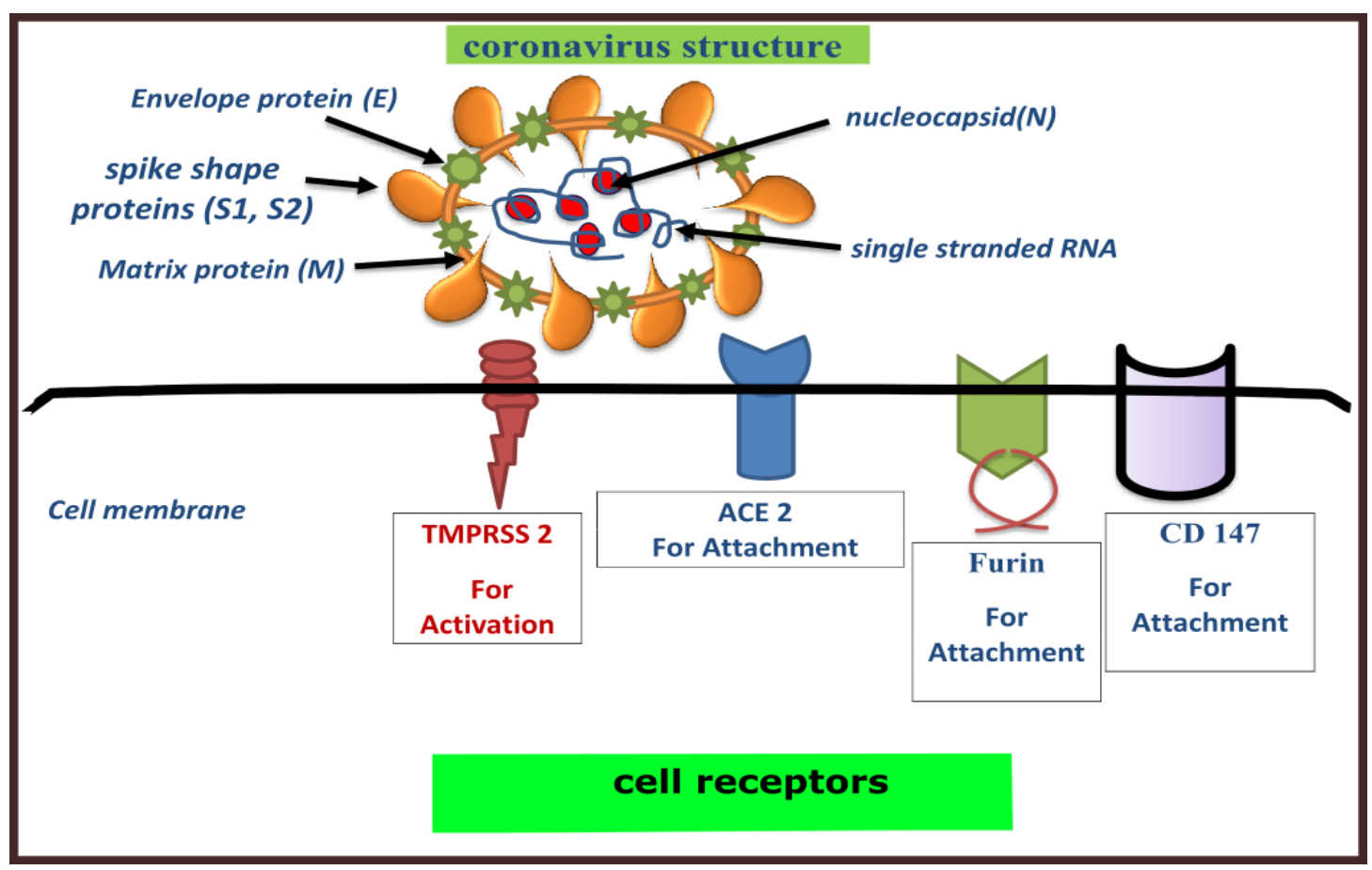

Figure 2. Showing fictional form for coronavirus (SARS-CoV-2) and its structures; also, possible host cell membrane receptors. 
During the massive spread of pandemic COVID-19, Attention to use tele-communication or teledentistry prior periodontal management to estimate the patient status also to diminish the risk of virus spread, quizzing if sickly person has common cold/ bronchitis symptoms and have went abroad national or internationally. In this significance, the treating team members necessarily use clinical judgment remotely and every possible precaution must be taken to prevent disease transmission (Pereira et al., 2020). In dental clinics, many necessary and successive measures must be taken during the rapid spread of the COVID-19 epidemic as follows; waiting room for one patient only , strict adherence to the infection control procedures, ideal steps of wearing and taking off all Personal Protective Equipment (PPE), including protection tools for all exposed skin, eyes, mouth, face and hands (Pereira et al., 2020). Before beginning of treatment, a patient rinsing with $1 \%$ or $1.5 \%$ hydrogen peroxide or $0.2 \%$ povidone also he should wear goggles and apron until ending of procedure (Pereira et al., 2020). Aerosols generation must be limited through using manual instruments and high-suction for saliva during the periodontal therapy and avoiding 3-in-1 chip syringe (Kharma et al., 2015).

\section{SARS-CoV-2 colonization into periodontal pockets}

A Periodontal pocket is a unique isolated site in the human body, presenting qualified biotic dynamics, with bidirectional linkage with the oral environment via periodontal crevicular fluid exudate on one direction and systemic circulation via gingival peripheral blood capillary networks on the other hand (Badran et al., 2020). Initial viral infection of periodontal tissues have occurred through direct contact of gingival epithelial cells exposed to the oral cavity with virus, or virus wandering and entrance via the blood supply or virally affected defense cells in the periodontal inflammatory transudate (C. S. Miller, 2014). The viral observations in periodontal pocket, have been affirmed such as Herpes simplex virus (HSV) type 1, type 4 (EBV) and type 5(HCMV) (Cappuyns et al., 2005).

The main gate of Coronavirus is proposed to be by emerged droplets results in a former nexus and habitation of cells in the oral environment (Lo Giudice, 2020). The main receptors to this virus are Angiotensin converting enzyme-2 (ACE-2) (Zou et al., 2020), Furin (proprotein convertase) (Izaguirre, 2019) and Cluster of Differentiation 147 (CD 147) (K. Wang et al., 2020) ; these receptors were highly expressed in fibroblasts of periodontium ligaments (Santos et al., 2015), in oral epithelial cells (Zhong et al., 2020) and the sulcular epithelium of periodontal pocket (Feldman et al., 2011).

Coronavirus' conjugation to membrane receptors, are suitable with an assumed attachment to periodontal pocket. This could encompass the sulcular/gingival epithelial lining also the gingival/periodontal fibroblasts (Badran et al., 2020). By different pathway, SARS-CoV can invade and reproduce in mononuclear cells (infecting T-Lymphocytes) but for a short span (X. Wang et al., 2020). Also, the invasion of endothelial cells by SARS-CoV-2 seems conceivable (Varga et al., 2020). It was hypothesized that periodontal pocket could represent a repository of SARS-CoV-2 depending on harmonious and feasible surveillances (Badran et al., 2020). 


\section{Blatant pandemic COVID-19 and calm pandemic periodontitis}

One of pathophysiological mechanisms of COVID-19 was introduced to be correlated to a 'cytokine storm' which appearing as supreme serum levels of proinflammatory interleukins. clinical studies in COVID-19 patients showed that manifestations of the cytokine storm matched up raised TH17 pathway (Wu \& Yang, 2020). Periodontal disease has a sophisticated interlace pathophysiology with increased affirmations of immunological participations; demonstrating that patients suffering from periodontal disease, having increased aggregate of Interleukin-17 (IL-17) in the serum as well as rise IL-17 output cells in gingival tissue (Graves, 2008).

A probable consortium between periodontal diseases and COVID-19 related detrimental consequences has been hypothesized. Future and present recognition of this correlation emphasizes the significance of maintaining periodontal conditions with continuous screening and the importance of keeping exacting oral hygiene in the COVID-19 interval and beyond. This probable association also tip across the potency of the existence of periodontal disease as catalyzer towards COVID-19 related detrimental effects (Sahni \& Gupta, 2020).

\section{Virtual existence of SARS-CoV-2 in saliva during periodontal diseases}

The salivaomics motif which constituting from genomics, transcriptomics, proteomics, metabonomics and microRNA (miRNA) screening was proposed by Wong in 2012 to appear from nowhere to existence ( Wong, 2012; Santosh et al., 2020) . Many salivary mediators have been used for the scientific periodontal disease's assessment. Porphyromonas gingivalis salivary kit which is depended on an enzyme-linked immunosorbent assay (ELISA) has been introduced and endued rapid results within 90 seconds with high sensitivity and a specificity (O'Brien-Simpson et al., 2015).

As periodontal diseases can be associated with more than 70 genes (Karimbux et al., 2012), salivary genomics represent recent appealing way for the periodontal diagnosis. After analyzing salivary DNA, it was legitimized that IL- 6 genetic mutations are one of considerable hazards for chronic periodontitis (Song et al., 2013).

Recently, viral infections identification by salivary biomarkers, such as viral DNA, RNA, antigens and antibodies was broadly used. Moreover, saliva considered to be more sensitive than serum in the assessment of human Herpesvirus-6 or human cytomegalovirus (Nefzi et al., 2015).For detecting the hepatitis $C$ virus, OraQuick ${ }^{\circledR}$ hepatitis $C$ virus rapid antibody test was used via a saliva samples (Parisi et al., 2014).

COVID-19 disease is very prevalent and super-contagious even to those who have all the means of protection and precautions from members of medical teams, especially at the beginning of diagnosis and diagnostic sampling via nasopharyngeal or oropharyngeal specimens, as a result of close proximity to potentially diseased individuals. In patients with condition such as thrombocytopenia, 
nasopharyngeal or oropharyngeal swabs could result in discomfort and provoke bleeding (Chan et al., 2020). In Hong Kong Public Health Laboratory Services Branch, Saliva from twelve confirmed COVID19 patients was gathered and submitted to nucleic acid extraction and real-time reverse transcriptionquantitative polymerase chain reaction. Virus was detected in $91.7 \%$ of the initial saliva samples. In 33 recovered patients, both nasopharyngeal and saliva specimens tested negative for COVID-19 (To et al., 2020).

Extraction of viral RNA from salivary fluid was a potent gateway for COVID-19 diagnosis and has the same fulfillment to the advisable swab-based collection specimens. with the universal insufficiency of swabs for diagnosis and huge increased COVID-19 patients, Salivary swabbing will be useful, and will be dimming the demand of health care specialists to round up samples (Anjum, 2020).

Potential diagnostic and prognostic biomarkers for COVID-19 disease, could be including salivary ELISA of antibodies against SARS-CoV-2, SARS-CoV-2 double-membrane extracellular vesicles (EVs) isolation, anti-SARS-CoV-2 surface proteins, viral titers load, CD4+/CD8+ T cells derived EVs, and proinflammatory cytokines. Indeed, an ideal indoor saliva test would be a nonreturnable ready device used by patients, avoiding contact to a prospect environmental virus infection hazard (Han \& Ivanovski 2020).

\section{Potential relevance between COVID-19 and periodontal diseases}

Gingiva that possesses angiotensin-converting enzyme 2 (ACE2) sensors would be given a conceivable track for SARS-coronavirus-2 entrance (Xu et al., 2020) (Balaji et al., 2020). In chronic periodontitis, gingival cells have established much amount of osteopontin, which resulting in elevated the protease furin level (Sharma \& Pradeep, 2007; Kumar et al., 2010). Besides furin, cathepsin L level is also heightened (Trabandt et al. 1995).

By assistance of furin and cathepsin, SARS-coronavirus-2 enable to invade the host cells. furin divides the S protein of the virus into S1 and S2 subunits (Zhong et al., 2020) (Hoffmann et al., 2020), then S1 subunit coheres to the angiotensin-converting enzyme 2 (ACE2) located at cell surfaces (Xia et al., 2020). then final fusion occurs via two ways, cysteine proteases cathepsin $B / L$ participation for endosomal fusion or serine protease participation for plasma membrane fusion (Xia et al., 2020). it can be assumed that the massive protease amount in chronic periodontitis could imaginably maximize endangering of an oral mediated SARS COV-2 infection (Xu et al., 2020). 


\section{Periodontal diseases as reflex of general health on COVID-19}

Reported hospital-acquired pneumonia complications in periodontally diseased patients are more likely to be developed because respiratory pathogens, including Chlamydia pneumoniae were hiding in oral cavity (Almeida-da-Silva et al., 2019; Scannapieco, 1999, 2006).

Adequacy of oral microbes to aggravate lung contagions may be explained; via (1) entrance of oral microbes inside the lower respiratory tract, predominantly in debilitating patients (2) changes of mucosal cells throughout the length of the respiratory system by actions of salivary enzymes, which thereby favoriting pathogens habitation (3) pro-inflammatory cytokines discharge through periodontal diseases, which enhancing coalescence to respiratory epithelium and settlement by respiratory microbes (Gomes-Filho et al., 2010; Varanat et al., 2017).

Oral status amelioration and refined regular periodontal interest diminish the succession or initiation of respiratory diseases, seriously in the senescent age and very ill patients (Azarpazhooh \& Leake, 2006). This population is also at extreme hazard for incubating critical complications concerned to COVID-19 (Boccardi et al., 2020; Swiss, 2020). Ameliorative periodontal condition in people of any age will diminish their endangering of developing any systemic diseases and this may eliminate the ailment of COVID-19 (Botros et al., 2020).

Massive effects of COVID-19 on oral/periodontal conditions appear to be multi-directional, immunerelated and supposedly indirect, expressed by several pathways, representing the pathological severity of coronavirus invasion/ stealth via mucosal surfaces (Dziedzic \& Wojtyczka, 2020).

\section{Periodontal treatment and COVID-19}

Aerosols with contaminated saliva that generated by any dental procedure, can seriously elevate airborne contamination with microbes (Micik et al., 1971). Aerosols are defined as tiny diameter airborne particles with lesser 50-micron which persisting as suspensor for extended time and increase incidence of circumferential dirtiness and gets pathway into respiratory system. Beside aerosols, airborne matters with oversized than 50-micron diameter which too large to persist as suspensor in air for protracted periods, are known as splatters. Splatters are considered as droplets get out vigorously in a defamatory way like a missile until they contact a subject (Harrel \& Molinari, 2004; Miller et al., 1971).

With talking, cough or sneeze, scattered virus can sustain for a longer interval as suspensor in surrounding area and may be prevailed via breathing in or communicate with infectious individuals. In 25-28 Celsius degrees, SARS-CoV-2 sticks on surfaces (inanimate flatness) across nine days, but its vitality is determined by the nature of the surfaces. It still infectious for several hours, 2-3 days, 5 days and more than 5 days in Aluminum and Copper, stainless steel and plastic, ceramics, and paper and glass respectively (Kampf et al., 2020). Selected aerosol paradigms showed that virion integrity can reach up to 16 hours pended in air under scanning electron microscope (Fears et al., 2020). 
The mechanism of defense against COVID-19 in dental clinical consist of three levels. The primary level is private preservative kit such as gloves, eyeglasses and masks. The secondary level is oral rinsing with antiseptics and the tripartite level is the use of high-speed suction and adjunctive high efficiency particulate air (HEPA) filters (Bauchner et al., 2020). By contact time fifteen second, $0.25 \%$ to $0.5 \%$ povidone-iodine (PVP-I) showed prompt viricidal activity against SARS-CoV-2 ('coronavirus') to lessen the danger of propagation of the infection in the practical field. Therefore, the 10\% (PVP-I) antiseptic formula should be diluted by $1: 20$, employing mixture of 0.5 cubic centimeter of $10 \%$ povidone iodine and 9.5 cubic centimeter of sterile water for single use at $0.5 \%$ povidone iodine concentration (Bidra et al., 2020).

Oxidizing agents such as citrox (Flavonoids as coronaviral chymotrypsin-like protease inhibitors) is used as mouth wash to constrict the virus's tonnage, encompassing potential SARS-CoV-2 transit. These oxidizing mouth rinses that comprise cyclodextrins combined with citrox could supply beneficial adjunctive periodontal therapy. Locally administered delivery systems that containing cyclodextrins combined with citrox or $0.5 \%$ povidone iodine, could diminish the SARS-CoV-2 virus's tonnage and minify the nasopharyngeal microbes, through coating aerosol and droplets throughout its rush from mouth (Carrouel et al., 2020).

Currently, the effects of COVID-19 around our planet are worsening continuously (kassaw \& Pandey, 2020). Medical and scientific research community learns more about COVID-19 with more blinded, randomized clinical trials will be performed. More future knowledge about novel coronavirus pathogenesis and its effect on periodontal tissue, microbiome interactions and possible genome/epigenome will open horizons in the relationship between COVID-19 and periodontal diseases.

\section{Conclusion}

As coronavirus was detected in saliva and epithelial cells of periodontal pocket have receptors to coronavirus attachment, this review concluded that there is close convergence between periodontal diseases and COVID-19.

\section{Conflicts of Interest:}

The authors declare no conflicts of interest.

\section{References}

- Abbas, A. A., Taylor, L. J., Dothard, M. I., Leiby, J. S., Fitzgerald, A. S., Khatib, L. A., Collman, R. G., \& Bushman, F. D. (2019). Redondoviridae, a family of small, circular DNA viruses of the human oro-respiratory tract associated with periodontitis and critical illness. Cell Host \& Microbe, 25(5), 719-729.

- Abramson, J. S., \& Mills, E. L. (1988). Depression of neutrophil function induced by viruses and its role in secondary microbial infections. Clinical Infectious Diseases, 10(2), 326-341.

- Adhikari, S. P., Meng, S., Wu, Y.-J., Mao, Y.-P., Ye, R.-X., Wang, Q.-Z., Sun, C., Sylvia, S., Rozelle, S., \& Raat, H. (2020). Epidemiology, causes, clinical manifestation and diagnosis, prevention and control of coronavirus disease (COVID-19) during the early outbreak period: a scoping review. Infectious Diseases of Poverty, 9(1), 1-12. 
- Almeida-da-Silva, C. L. C., Alpagot, T., Zhu, Y., Lee, S. S., Roberts, B. P., Hung, S.-C., Tang, N., \& Ojcius, D. M. (2019). Chlamydia pneumoniae is present in the dental plaque of periodontitis patients and stimulates an inflammatory response in gingival epithelial cells. Microbial Cell, 6(4), 197.

- Anjum, R. (2020). Role of Saliva as a Viable Bio Sample for COVID-19 Detection. Biomedica, 36.

- Azarpazhooh, A., \& Leake, J. L. (2006). Systematic review of the association between respiratory diseases and oral health. Journal of Periodontology, 77(9), 1465-1482.

- Badran, Z., Gaudin, A., Struillou, X., Amador, G., \& Soueidan, A. (2020). Periodontal pockets: a potential reservoir for SARS-CoV-2? Medical Hypotheses, 109907.

- Balaji, T. M., Varadarajan, S., Rao, U. S. V., Raj, A. T., Patil, S., Arakeri, G., \& Brennan, P. A. (2020). Oral cancer and periodontal disease increase the risk of COVID 19? A mechanism mediated through furin and cathepsin overexpression. Medical Hypotheses.

- Bauchner, H., Fontanarosa, P. B., \& Livingston, E. H. (2020). Conserving supply of personal protective equipment-a call for ideas. Jama, 323(19), 1911.

- Bidra, A. S., Pelletier, J. S., Westover, J. B., Frank, S., Brown, S. M., \& Tessema, B. (2020). Rapid In-Vitro Inactivation of Severe Acute Respiratory Syndrome Coronavirus 2 (SARS-CoV-2) Using Povidone-lodine Oral Antiseptic Rinse. Journal of Prosthodontics.

- Boccardi, V., Ruggiero, C., \& Mecocci, P. (2020). COVID-19: A geriatric emergency. Multidisciplinary Digital Publishing Institute.

- Botros, N., Iyer, P., \& Ojcius, D. M. (2020). News and Perspectives Is There an Association Between Oral Health and Severity of COVID-19 Complications? Biomedical Journal.

- Cappuyns, I., Gugerli, P., \& Mombelli, A. (2005). Viruses in periodontal disease-a review. Oral Diseases, 11(4), 219-229.

- Carrouel, F., Conte, M. P., Fisher, J., Gonçalves, L. S., Dussart, C., Llodra, J. C., \& Bourgeois, D. (2020). COVID-19: A recommendation to examine the effect of mouthrinses with $\beta$-cyclodextrin combined with citrox in preventing infection and progression. Multidisciplinary Digital Publishing Institute.

- Chan, J. F.-W., Yuan, S., Kok, K.-H., To, K. K.-W., Chu, H., Yang, J., Xing, F., Liu, J., Yip, C. C.-Y., \& Poon, R. W.-S. (2020). A familial cluster of pneumonia associated with the 2019 novel coronavirus indicating person-to-person transmission: a study of a family cluster. The Lancet, 395(10223), 514523.

- Contreras, A., Botero, J. E., \& Slots, J. (2014). Biology and pathogenesis of cytomegalovirus in periodontal disease. Periodontology 2000, 64(1), 40-56.

- Dziedzic, A., \& Wojtyczka, R. (2020). The impact of coronavirus infectious disease 19 (COVID-19) on oral health. Oral Diseases.

- Fears, A. C., Klimstra, W. B., Duprex, P., Hartman, A., Weaver, S. C., Plante, K. C., Mirchandani, D., Plante, J. A., Aguilar, P. V, \& Fernandez, D. (2020). Comparative dynamic aerosol efficiencies of three emergent coronaviruses and the unusual persistence of SARS-CoV-2 in aerosol suspensions. MedRxiv.

- Fehr, A. R., \& Perlman, S. (2015). Coronaviruses: an overview of their replication and pathogenesis. In Coronaviruses (pp. 1-23). Springer.

- Feldman, M., La, V. D., Bedran, T. B. L., Spolidorio, D. M. P., \& Grenier, D. (2011). Porphyromonas gingivalis-mediated shedding of extracellular matrix metalloproteinase inducer (EMMPRIN) by oral epithelial cells: a potential role in inflammatory periodontal disease. Microbes and Infection, 13(1415), 1261-1269.

- Gomes-Filho, I. S., Passos, J. S., \& Seixas da Cruz, S. (2010). Respiratory disease and the role of oral bacteria. Journal of Oral Microbiology, 2(1), 5811.

- Gorbalenya, A. E., Baker, S. C., Baric, R., Groot, R. J. de, Drosten, C., Gulyaeva, A. A., Haagmans, B. L., Lauber, C., Leontovich, A. M., \& Neuman, B. W. (2020). Severe acute respiratory syndromerelated coronavirus: The species and its viruses-a statement of the Coronavirus Study Group.

- Graves, D. (2008). Cytokines that promote periodontal tissue destruction. Journal of Periodontology, $79,1585-1591$.

- Han P, I. S. (2020). Saliva-Friend and Foe in the COVID-19 Outbreak. Diagnostics., 10(5), 290.

- Harrel, S. K., \& Molinari, J. (2004). Aerosols and splatter in dentistry: a brief review of the literature and infection control implications. The Journal of the American Dental Association, 135(4), 429-437.

- Harte, J. A. (2010). Standard and transmission-based precautions: an update for dentistry. The Journal of the American Dental Association, 141(5), 572-581.

- Heng, M. C. Y., Heng, S. Y., \& Allen, S. G. (1994). Co-infection and synergy of human immunodeficiency virus-1 and herpes simplex virus-1. The Lancet, 343(8892), 255-258.

- Hoffmann, M., Kleine-Weber, H., Schroeder, S., Krüger, N., Herrler, T., Erichsen, S., Schiergens, T. 
S., Herrler, G., Wu, N.-H., \& Nitsche, A. (2020). SARS-CoV-2 cell entry depends on ACE2 and TMPRSS2 and is blocked by a clinically proven protease inhibitor. Cell.

- Hu, Y., Li, W., Gao, T., Cui, Y., Jin, Y., Li, P., Ma, Q., Liu, X., \& Cao, C. (2017). The severe acute respiratory syndrome coronavirus nucleocapsid inhibits type I interferon production by interfering with TRIM25-mediated RIG-I ubiquitination. Journal of Virology, 91(8).

- Huang, C., Lokugamage, K. G., Rozovics, J. M., Narayanan, K., Semler, B. L., \& Makino, S. (2011). SARS coronavirus nsp1 protein induces template-dependent endonucleolytic cleavage of mRNAs: viral mRNAs are resistant to nsp1-induced RNA cleavage. PLoS Pathog, 7(12), e1002433.

- Imai, K., \& Ogata, Y. (2020). How Does Epstein-Barr Virus Contribute to Chronic Periodontitis? International Journal of Molecular Sciences, 21(6), 1940.

- Izaguirre, G. (2019). The proteolytic regulation of virus cell entry by furin and other proprotein convertases. Viruses, 11(9), 837.

- Kampf, G., Todt, D., Pfaender, S., \& Steinmann, E. (2020). Persistence of coronaviruses on inanimate surfaces and their inactivation with biocidal agents. Journal of Hospital Infection, 104(3), 246-251.

- Karimbux, N. Y., Saraiya, V. M., Elangovan, S., Allareddy, V., Kinnunen, T., Kornman, K. S., \& Duff, G. W. (2012). Interleukin-1 gene polymorphisms and chronic periodontitis in adult whites: a systematic review and meta-analysis. Journal of Periodontology, 83(11), 1407-1419.

- kassaw, C., \& Pandey, D. (2020). The prevalence of general anxiety disorder and its associated factors among women's attending at the perinatal service of Dilla University referral hospital, Dilla town, Ethiopia, April, 2020 in Covid pandemic. Heliyon, 6(11), e05593. https://doi.org/https://doi.org/10.1016/j.heliyon.2020.e05593

- Kharma, M. Y., Alalwani, M. S., Amer, M. F., Tarakji, B., \& Aws, G. (2015). Assessment of the awareness level of dental students toward Middle East Respiratory Syndrome-coronavirus. Journal of International Society of Preventive \& Community Dentistry, 5(3), 163.

- Khongsai, L., Anal, T. S. S. C., A.S., R., Kh., T. S., Shah, M. K., \& Pandey, D. (2020). Combating the Spread of COVID-19 Through Community Participation. Global Social Welfare. https://doi.org/10.1007/s40609-020-00174-4

- Kindler, E., Thiel, V., \& Weber, F. (2016). Interaction of SARS and MERS coronaviruses with the antiviral interferon response. Advances in Virus Research, 96, 219-243.

- Kumar, V., Behera, R., Lohite, K., Karnik, S., \& Kundu, G. C. (2010). p38 kinase is crucial for osteopontin-induced furin expression that supports cervical cancer progression. Cancer Research, 70(24), 10381-10391.

- Lo Giudice, R. (2020). The Severe Acute Respiratory Syndrome Coronavirus-2 (SARS CoV-2) in Dentistry. Management of Biological Risk in Dental Practice. International Journal of Environmental Research and Public Health, 17(9), 3067.

- Micik, R. E., Miller, R. L., \& Leong, A. C. (1971). Studies on dental aerobiology: Ill. Efficacy of surgical masks in protecting dental personnel from airborne bacterial particles. Journal of Dental Research, $50(3), 626-630$.

- Miller, C. S. (2014). Viruses: are they really culprits for periodontal disease? A critical review? Journal of Investigative and Clinical Dentistry, 5(3), 243.

- Miller, R. L., Micik, R. E., Abel, C., \& Ryge, G. (1971). Studies on dental aerobiology: II. Microbial splatter discharged from the oral cavity of dental patients. Journal of Dental Research, 50(3), 621625.

- Nefzi, F., Ben Salem, N. A., Khelif, A., Feki, S., Aouni, M., \& Gautheret-Dejean, A. (2015). Quantitative analysis of human herpesvirus- 6 and human cytomegalovirus in blood and saliva from patients with acute leukemia. Journal of Medical Virology, 87(3), 451-460.

- O'Brien-Simpson, N. M., Burgess, K., Brammar, G. C., Darby, I. B., \& Reynolds, E. C. (2015). Development and evaluation of a saliva-based chair-side diagnostic for the detection of Porphyromonas gingivalis. Journal of Oral Microbiology, 7(1), 29129.

- PANDEY, D., PANDEY, B. K., NOIBI, T. O., BABU, S., PATRA, P. M., KASSAW, C., ENBEYLE, W., KADAM, S. A., \& CANETE, J. J. O. (2020). COVID-19: UNLOCK 1.0 RISK, TEST, TRANSMISSION, INCUBATION AND INFECTIOUS PERIODS AND REPRODUCTION OF NOVEL COVID-19 PANDEMIC. Asian Journal of Advances in Medical Science, 23-28.

- Parisi, M. R., Soldini, L., Vidoni, G., Mabellini, C., Belloni, T., Brignolo, L., Negri, S., Schlusnus, K., Dorigatti, F., \& Lazzarin, A. (2014). Point-of-care testing for HCV infection: recent advances and implications for alternative screening. The New Microbiologica, 37(4), 449-457.

- Pereira, L. J., Pereira, C. V., Murata, R. M., Pardi, V., \& Pereira-Dourado, S. M. (2020). Biological and social aspects of Coronavirus Disease 2019 (COVID-19) related to oral health. Brazilian Oral 
Research, 34.

- Sahni, V., \& Gupta, S. (2020). COVID-19 \& Periodontitis: The cytokine connection. Medical Hypotheses, 109908.

- Santos, C. F., Morandini, A. C., Dionísio, T. J., Faria, F. A., Lima, M. C., Figueiredo, C. M., ColombiniIshikiriama, B. L., Sipert, C. R., Maciel, R. P., \& Akashi, A. P. (2015). Functional local reninangiotensin system in human and rat periodontal tissue. PloS One, 10(8), e0134601.

- Santosh, T. S., Parmar, R., Anand, H., Srikanth, K., \& Saritha, M. (2020). A review of salivary diagnostics and its potential implication in detection of Covid-19. Cureus, 12(4).

- Scannapieco, F. A. (1999). Role of oral bacteria in respiratory infection. Journal of Periodontology, 70(7), 793-802.

- Scannapieco, F. A. (2006). Pneumonia in nonambulatory patients: the role of oral bacteria and oral hygiene. The Journal of the American Dental Association, 137, S21-S25.

- Sharma, C. G., \& Pradeep, A. R. (2007). Plasma and crevicular fluid osteopontin levels in periodontal health and disease. Journal of Periodontal Research, 42(5), 450-455.

- Siu, K.-L., Kok, K.-H., Ng, M.-H. J., Poon, V. K. M., Yuen, K.-Y., Zheng, B.-J., \& Jin, D.-Y. (2009). Severe acute respiratory syndrome coronavirus $M$ protein inhibits type I interferon production by impeding the formation of TRAF3. TANK. TBK1/IKKE complex. Journal of Biological Chemistry, 284(24), 16202-16209.

- Song, G. G., Choi, S. J., Ji, J. D., \& Lee, Y. H. (2013). Association between tumor necrosis factor-a promoter- $308 \mathrm{~A} / \mathrm{G},-238 \mathrm{~A} / \mathrm{G}$, interleukin-6-174 G/C and-572 G/C polymorphisms and periodontal disease: a meta-analysis. Molecular Biology Reports, 40(8), 5191-5203.

- Swiss, A. O. M. S. (2020). COVID-19 pandemic: triage for intensive-care treatment under resource scarcity. Swiss Medical Weekly, 150, w20229.

- Tanaka, T., Kamitani, W., DeDiego, M. L., Enjuanes, L., \& Matsuura, Y. (2012). Severe acute respiratory syndrome coronavirus nsp1 facilitates efficient propagation in cells through a specific translational shutoff of host mRNA. Journal of Virology, 86(20), 11128-11137.

- To, K. K.-W., Tsang, O. T.-Y., Yip, C. C.-Y., Chan, K.-H., Wu, T.-C., Chan, J. M.-C., Leung, W.-S., Chik, T. S.-H., Choi, C. Y.-C., \& Kandamby, D. H. (2020). Consistent detection of 2019 novel coronavirus in saliva. Clinical Infectious Diseases.

- Varanat, M., Haase, E. M., Kay, J. G., \& Scannapieco, F. A. (2017). Activation of the TREM-1 pathway in human monocytes by periodontal pathogens and oral commensal bacteria. Molecular Oral Microbiology, 32(4), 275-287.

- Varga, Z., Flammer, A. J., Steiger, P., Haberecker, M., Andermatt, R., Zinkernagel, A. S., Mehra, M. R., Schuepbach, R. A., Ruschitzka, F., \& Moch, H. (2020). Endothelial cell infection and endotheliitis in COVID-19. The Lancet, 395(10234), 1417-1418.

- Wahba, L., Jain, N., Fire, A. Z., Shoura, M. J., Artiles, K. L., McCoy, M. J., \& Jeong, D. E. (2020). Identification of a pangolin niche for a 2019-nCoV-like coronavirus through an extensive metametagenomic search. BioRxiv.

- Wang, K., Chen, W., Zhou, Y.-S., Lian, J.-Q., Zhang, Z., Du, P., Gong, L., Zhang, Y., Cui, H.-Y., \& Geng, J.-J. (2020). SARS-CoV-2 invades host cells via a novel route: CD147-spike protein. BioRxiv.

- Wang, X., Xu, W., Hu, G., Xia, S., Sun, Z., Liu, Z., Xie, Y., Zhang, R., Jiang, S., \& Lu, L. (2020). SARS-CoV-2 infects T lymphocytes through its spike protein-mediated membrane fusion. Cellular \& Molecular Immunology, 1-3.

- Wax, R. S., \& Christian, M. D. (2020). Practical recommendations for critical care and anesthesiology teams caring for novel coronavirus (2019-nCoV) patients. Canadian Journal of Anesthesia/Journal Canadien d'anesthésie, 1-9.

- Wong, D. T. W. (2012). Salivaomics. The Journal of the American Dental Association, 143, 19S24S.

- Wong, J., Goh, Q. Y., Tan, Z., Lie, S. A., Tay, Y. C., Ng, S. Y., \& Soh, C. R. (2020). Preparing for a COVID-19 pandemic: a review of operating room outbreak response measures in a large tertiary hospital in Singapore. Canadian Journal of Anesthesia/Journal Canadien d'anesthésie, 1-14.

- Wu, D., \& Yang, X. O. (2020). TH17 responses in cytokine storm of COVID-19: An emerging target of JAK2 inhibitor Fedratinib. Journal of Microbiology, Immunology and Infection.

- Xia, S., Liu, M., Wang, C., Xu, W., Lan, Q., Feng, S., Qi, F., Bao, L., Du, L., \& Liu, S. (2020). Inhibition of SARS-CoV-2 (previously 2019-nCoV) infection by a highly potent pan-coronavirus fusion inhibitor targeting its spike protein that harbors a high capacity to mediate membrane fusion. Cell Research, 30(4), 343-355.

- Xu, H., Zhong, L., Deng, J., Peng, J., Dan, H., Zeng, X., Li, T., \& Chen, Q. (2020). High expression of ACE2 receptor of 2019-nCoV on the epithelial cells of oral mucosa. International Journal of Oral 
Science, 12(1), 1-5.

- Zhang, H., Kang, Z., Gong, H., Xu, D., Wang, J., Li, Z., Cui, X., Xiao, J., Meng, T., \& Zhou, W. (2020). The digestive system is a potential route of 2019-nCov infection: a bioinformatics analysis based on single-cell transcriptomes. BioRxiv.

- Zhong, M., Lin, B., Gao, H., Young, A. J., Wang, X., Liu, C., Wu, K., Liu, M., Chen, J., \& Huang, J. (2020). Significant expression of FURIN and ACE2 on oral epithelial cells may facilitate the efficiency of SARS-CoV-2 entry. BioRxiv.

- Zhou, P., Yang, X.-L., Wang, X.-G., Hu, B., Zhang, L., Zhang, W., Si, H.-R., Zhu, Y., Li, B., \& Huang, C.-L. (2020). A pneumonia outbreak associated with a new coronavirus of probable bat origin. Nature, 579(7798), 270-273.

- Zou, X., Chen, K., Zou, J., Han, P., Hao, J., \& Han, Z. (2020). Single-cell RNA-seq data analysis on the receptor ACE2 expression reveals the potential risk of different human organs vulnerable to 2019-nCoV infection. Frontiers of Medicine, 1-8. 